\title{
Electromagnetic disturbances induced by nuclear tests in North Korea
}

\author{
Xuemin Zhang ${ }^{1, *}$, Yalu Wang ${ }^{1}$, Yongxin $\mathrm{Gao}^{2}$, and Jing Liu ${ }^{1}$ \\ ${ }^{1}$ Institute of Earthquake Forecasting, China Earthquake Administration, Beijing, China \\ ${ }^{2}$ Hefei University of Technology, Hefei, China
}

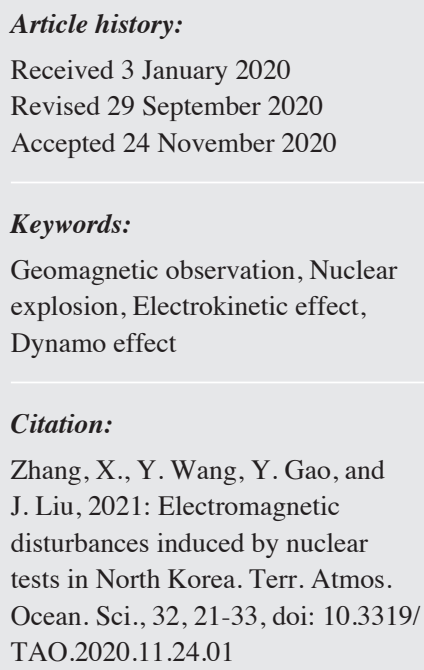

\begin{abstract}
In this study, three magnetometer stations in China and four co-located magnetometers and geoelectric field detectors in Japan were primarily used for observing co-seismic signatures excited by nuclear explosions conducted in North Korea between 2006 - 2017. The observations in Japan did not measure considerable magnitudes of the co-seismic electromagnetic (EM) signals corresponding to the geomagnetic and geoelectric fields at large distances from the explosion source. However, the geomagnetic field detectors in northeast China detected clear co-seismic signatures, shortly after the arrival time of the seismic waves. On the day of the most powerful blast on 3 September 2017, the horizontal component of the geomagnetic field with a maximum amplitude of $\pm 5 \mathrm{nT}$ was measured at the Changchun station in China, located at a distance of less than $500 \mathrm{~km}$ from the explosion source. In order to understand the measured signals, three mechanisms that can induce these signals were simulated. The electrokinetic and dynamo effects were observed to primarily contribute to the formation of the surface-wave-related EM signals, whereas the shaking and vibration of the instrument caused the continuous oscillation seen in the geomagnetic observations.
\end{abstract}

\section{INTRODUCTION}

In the previous studies, many co-seismic electromagnetic (EM) signals have been widely observed after strong earthquakes. Abdul Azeez et al. (2009) showed the presence of co-seismic EM signals in the magnetotelluric (MT) observations after the Bhuj Mw 7.6 earthquake occurred in India on 26 January 2001. In their measurements, the amplitude of the $\mathrm{E}_{\mathrm{x}}$ (northward) and $\mathrm{E}_{\mathrm{y}}$ (eastward) components of the electric field in the $0.1-10 \mathrm{~Hz}$ frequency range was $\pm 1.5 \mathrm{mV} \mathrm{km}^{-1}$ and $\pm 2 \mathrm{nT} \mathrm{s}^{-1}$ for the vertical component of the magnetic field. This was less than $\pm 1 \mathrm{nT} \mathrm{s}^{-1}$ in the northward $\left(\mathrm{H}_{\mathrm{x}}\right)$ and eastward $\left(\mathrm{H}_{\mathrm{y}}\right)$ directions measured at the MT site located at a distance of $\sim 350 \mathrm{~km}$. Honkura et al. (2000) also observed co-seismic EM signals by using the MT data, and the large amplitude recorded at a station located farther away was observed to be correlated with the low resistivity underground at the location. Tang et al. (2010) observed the electromagnetic co-seismic effect around the aftershocks of the Wenchuan Ms 8.0 earthquake. Corresponding to the strongest aftershock of Ms 6.4 that occurred in Qingchuan

\footnotetext{
* Corresponding author

E-mail: zhangxm96@126.com
}

on 25 May 2008, maximum amplitudes of the electric field of a few $\mathrm{mV} / \mathrm{km}$ and the magnetic field signals of $\pm 1 \mathrm{nT}$ amplitudes respectively were measured at a station located at $116.2 \mathrm{~km}$ from the epicenter. Iyemori et al. (2005) reported the geomagnetic pulsations caused by the Sumatra earthquake on 26 December 2004. In their study, Pc5 pulsations with a period of $3.6 \mathrm{~min}$ were detected at a distance of $1500 \mathrm{~km} 12$ min after the main shock in Phimai, Thailand. In addition, Pc 3 pulsations with a period of $30 \mathrm{~s}$, possibly induced by ionospheric dynamo effect, were measured by the Tonghai station in China located $1000 \mathrm{~km}$ beyond Phimai in latitude. Nagao et al. (2000) reported changes in the co-seismic geoelectric potential resulting due to the earthquakes in Japan at nearby distances of tens of meters and farthest distances of less than $15 \mathrm{~km}$. The first part of the signals was oscillatory and synchronized with the seismic waves, whereas the second part exhibited a rise time of a few seconds and a decay time of $0.1-1 \mathrm{~h}$, possibly induced by the subsurface hydrological change. In their paper, coseismic signals in the geomagnetic field with a maximum amplitude of $\pm 1 \mathrm{nT}$ of the Hy component were reported to be measured at a station located $12 \mathrm{~km}$ away from the 
epicenter. Widarto et al. (2009) reported changes in the co-seismic geoelectrical potential measured at a station located at $220 \mathrm{~km}$ from the epicenter. An amplitude of up to $400 \mathrm{mV} \mathrm{km}^{-1}$ was measured $40 \mathrm{~s}$ after the Mw 7.9 earthquake in Bengkulu of Sumatra on 4 June 2000 and this observation is consistent with the arrival of seismic P-wave (longitudinal wave, http://www.isc.ac.uk/standards/phases/). On 11 March 2011, the traveling Rayleigh waves of the Mw 9.0 Tohoku-Oki earthquake induced excitation of geomagnetic pulsations, which were measured with pronounced periods of $200 \mathrm{~s}$ and amplitudes of $0.2-1.2 \mathrm{nT}$ at the epicentral distances of $190-4600 \mathrm{~km}$ (Yen et al. 2015). Liu et al. (2017) and Chen et al. (2019) found that during the Mw 6.6 Meinong earthquake on 6 February 2016 and Mw 6.2 Hualien earthquake on 6 February 2018, the magnetometer, the geophone, and infrasound data all detected clear co-seismic signatures. In addition, the induction magnetometer recorded high-frequency pulsations similar to seismic waves and low-frequency variations caused by instrument shaking or a change in the underground water level. Other than natural earthquakes, explosions can also cause perturbations in electromagnetic observations. Anisimov et al. (1985) reported the magnetic and electric measurements performed during a series of industrial explosions in the Khorezms region of the USSR. They found that the seismic, electric, and magnetic perturbations occurred practically simultaneously. Frequencies of the electromagnetic and seismic vibrations of about $1 \mathrm{~Hz}$, amplitude of electric field between $1-10 \mu \mathrm{V} \mathrm{m}^{-1}$, and that of the magnetic field of about several nT were measured in the range of $1.5-5.5 \mathrm{~km}$. Sweeney (1989) reported ultra-low frequency (ULF) electromagnetic pulses observed during underground nuclear explosions, which might have been caused by products of nuclear detonation such as gamma radiation. At distances of 5 to $10 \mathrm{~km}$ from the explosion test area, the amplitudes of the electric and magnetic components of the EM signals exceeded tens of $\mu \mathrm{V} / \mathrm{m}$ and hundreds of $\mathrm{pT}$, respectively (Sweeney 1989). All these observations illustrate the sensitive changes occurring in the EM field due to the seismic waves induced by natural earthquakes or artificial blasts on a large scale.

In terms of the relation between the EM signals and seismic waves, different effects have been suggested, such as the widely accepted electrokinetic, piezomagnetic, and EM induction effects due to ground motion. A dipole model was developed for calculating the EM impulses produced by an earthquake from several mechanoelectromagnetic effects (Gershenzon et al. 1993). Based on a series of field experiments, Garambois and Dietrich (2001) demonstrated that the magnetic field mainly depended on the shear modulus of grains and on the viscosity of the fluid and its dielectric constant. Yamazaki (2011) showed that the piezomagnetic signals increased from $0.2 \mathrm{nT}$ for a uniformly magnetized crust to $0.5 \mathrm{nT}$ for a non-uniformly magnetized one, which may be a plausible mechanism leading to detectable co- seismic magnetic signals near the magnetization boundaries after strong earthquakes. Gao et al. (2014) studied the properties of EM signals generated by an earthquake due to the motional induction effect, i.e., from the motion of the conducting crust across the Earth's magnetic field, and they demonstrated that the motional effect dominated the mechanoelectric conversion under low frequency and high conductivity conditions. Surkov et al. (2018) discussed the co-seismic electromagnetic effects, including the electrokinetic and geomagnetic inductive effect. Their results illustrated that the magnitude and polarization of the co-seismic electromagnetic signals depended strongly on the type of the seismic wave and the local crust parameters such as the streaming potential coupling coefficient, conductivity, inhomogeneity, etc. To date, the sources of a large number of EM measured signals have not been determined. Further studies are required to understand the response of the EM field to the different dynamic waves, and also to improve the knowledge of the occurrence of precursors in the EM field before strong earthquakes.

In this paper, co-seismic magnetic signatures have been studied around the location of the nuclear tests conducted in North Korea, and the main mechanisms that contribute to these signatures have been illustrated using digital simulations.

\section{BACKGROUND INFORMATION}

Between 2006 - 2017, nuclear tests were detected six times at almost the same position in North Korea (Table 1), which attracted considerable attention from many countries. On 3 September 2017, the magnitude of the explosions recorded by seismograms reached a maximum value of Ms 6.3. Subsequently, this nuclear site was destroyed, and no tests have been conducted ever since. In this paper, we describe the analysis of the last two tests in detail in the next section. These tests were chosen due to their larger magnitude among all the events and have been analyzed mainly using the geomagnetic field data measured in the surrounding areas of China and Japan.

In China, the geomagnetic field studies started in the 1960s, and a Geomagnetic Observational Network has also been constructed ever since. At present, more than 100 stations are being operated for detecting variations in the geomagnetic field with a sampling rate of $1 \mathrm{~min}$. In addition, about 40 stations employing the fluxgate magnetometer observe the three-component basic geomagnetic field with a sampling rate of $1 \mathrm{~s}$. In this work, we have used the data only from the latter to reveal the high frequency signals. The observation system used in China is HFDZ-M15, consisting of two instruments of the DHZ three-component fluxgate magnetometer developed by Denmark (DMI Suspended Fluxgate Magnetometer), and the Overhouser Magnetometer made by Canada (http://www.geomag.org.cn/default.aspx). 
In Japan, data from 4 stations, including the geomagnetic, geoelectric, and atmospheric electric field data, has been published by the Japan Meteorological Agency. The data in seconds is available since the 1990s. To illustrate the spatial correlation between the stations and the blast source, Fig. 1 shows the locations of the geomagnetic stations from which the data have been used in this study. Out of these, four stations are in China in Changchun $(\mathrm{CNH})$, Dedu (DED), Dalian (DLG), and Urumqi (WMQ), and four are in Japan at Kakioka (KAK), Memambetsu (MMB), Kanoya (KNY), and Chichijima (CBI). It can be seen that northeast China is close to North Korea, and this provides a good opportunity to study the disturbances in the geomagnetic field induced by underground explosions.

\section{DATA ANALYSIS}

\subsection{Co-Seismic Signatures in Northeast China on 9 September 2016}

At UT 00:30:00.5 on 9 September 2016, a nuclear test was conducted, as listed in Table 1 , at a site located at a longitude of $129.1^{\circ} \mathrm{E}$ and latitude of $41.4^{\circ} \mathrm{N}$. The magnitude was inverted using seismograms as Ms 5.0. Disturbances were detected in the signals recorded by the geomagnetic field observation stations in China in this duration. As shown in Fig. 2, the horizontal $(\mathrm{H})$ and vertical downward (Z) components of the geomagnetic field were measured at the Changchun and Dedu stations, which are located at a distance of approximately 460 and $825 \mathrm{~km}$ respectively from the blast site. We have used a moving average window of $31 \mathrm{~s}$ to remove the background trend in the observations. From the figure, it can be seen that the data from the Changchun station (Fig. 2a) can be divided into three sections. About $70 \mathrm{~s}$ after the explosion, a few high-frequency signals were recorded first, and the amplitude in both the horizontal and vertical components was found to increase. $80 \mathrm{~s}$ later, a long period modulation occurred. After $300 \mathrm{~s}$, maximum modulations appeared with a much longer period of approximately $40 \mathrm{~s}$ and an amplitude of $\pm 0.4 \mathrm{nT}$. These three-segment variations with different frequency bands could be attributed to the primary waves ( $\mathrm{P}$-waves or longitudinal waves), shear waves (S-waves), and surface waves, respectively, according to their arrival times. At the Dedu station (Fig. 2b), disturbances around $60-120 \mathrm{~s}$ were not as clear as those recorded at the Changchun station. This could be due to its long distance from the explosion source in North Korea. Between 240 - 360 s, strong disturbances with amplitudes similar to those recorded at the Changchun station were observed. However, these signals are delayed by approximately $20 \mathrm{~s}$ in phase as compared to the signals measured at Changchun. It is strange for these two stations to detect the same waves within such a small duration, and this indicates that the wave velocity at the Dedu station is reduced to approximately half the values at the Changchun

Table 1. A list of the nuclear events conducted in Korea from 2006 to 2017.

\begin{tabular}{cccccc}
\hline No. & Date $(\mathbf{y y y y}-\mathbf{m m}-\mathbf{d d})$ & $\mathbf{U T}(\mathbf{h h : m m : s s})$ & Latitude $\left(^{\circ}\right)$ & Longitude $\left(^{\circ}\right)$ & $\mathbf{M s}$ \\
\hline 1 & $2006-10-9$ & $01: 35: 28.1$ & 41.4 & 129.0 & 4.0 \\
2 & $2009-5-25$ & $00: 54: 43.1$ & 41.3 & 129.0 & 4.3 \\
3 & $2013-2-12$ & $02: 57: 52.8$ & 41.3 & 129.0 & 4.9 \\
4 & $2016-1-6$ & $01: 30: 01.9$ & 41.3 & 129.1 & 4.9 \\
5 & $2016-9-9$ & $00: 30: 00.5$ & 41.4 & 129.1 & 5.0 \\
6 & $2017-9-3$ & $03: 30: 01.6$ & 41.35 & 129.11 & 6.3 \\
\hline
\end{tabular}

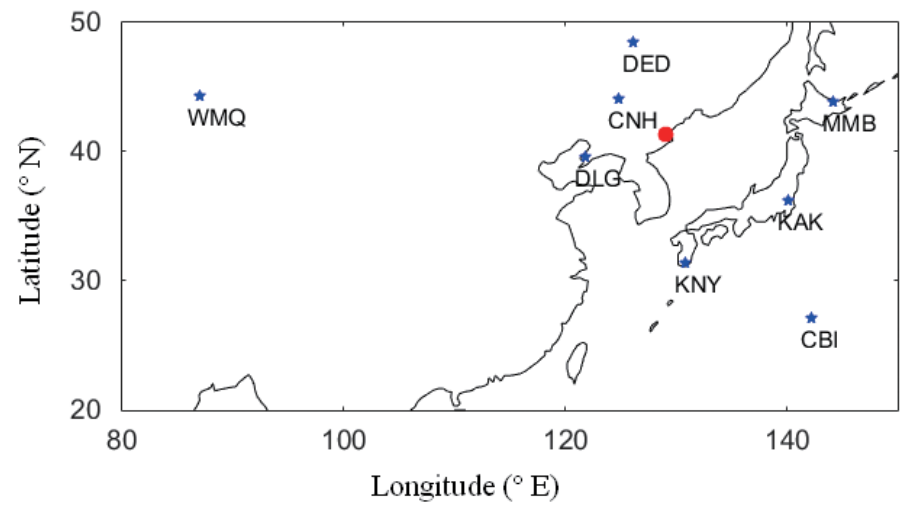

Fig. 1. Locations of the nuclear explosions (red circle) and eight geomagnetic stations (blue star). 

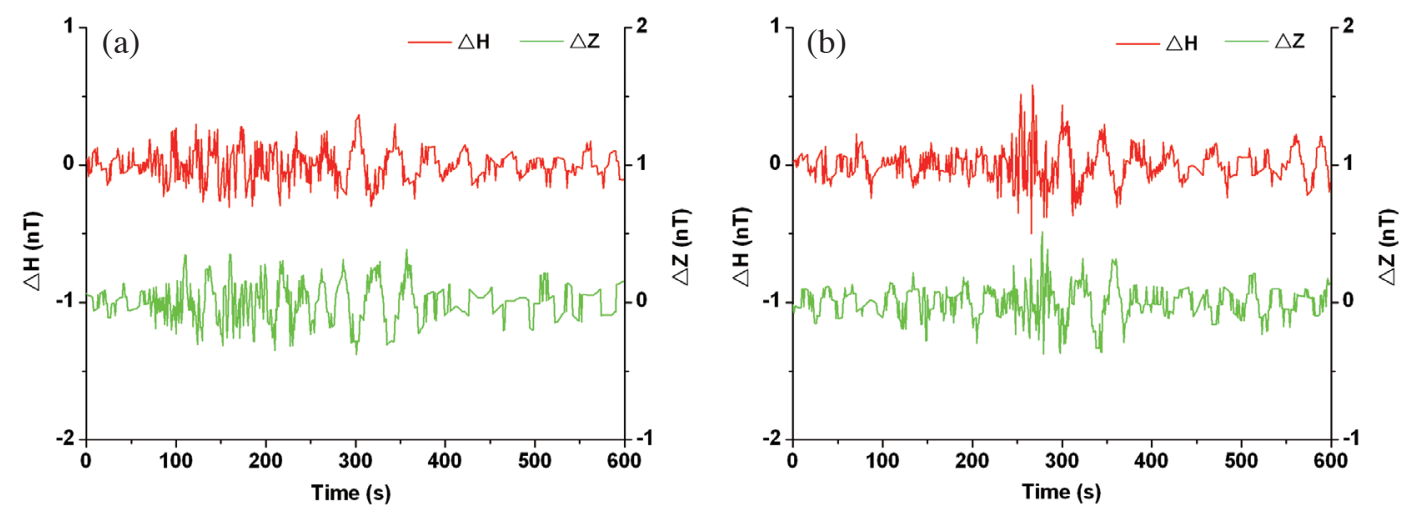

Fig. 2. Variation in the horizontal and vertical magnetic field signals in northeast China measured on 9 September 2016 at the (a) Changchun and (b) Dedu stations ( $\mathrm{t}=0$ is the time of the nuclear explosion).

station. The closeness in the arrival time of the signals at both the stations and the long period indicate that the final disturbances might not have been directly related to seismic waves, but are more likely to be geomagnetic pulsations.

\subsection{Electromagnetic Disturbances on 3 September 2017}

\subsubsection{Co-Seismic Geomagnetic Signals in Northeast China}

At UT 03:30:01.6 on 3 September 2017, another nuclear explosion took place, as listed in Table 1 , at $41.35^{\circ} \mathrm{N}$, $129.11^{\circ} \mathrm{E}$, with the magnitude of Ms 6.3. Figure 3 shows the geomagnetic field data that was measured at three stations within a duration of $10 \mathrm{~min}$ after the explosion. The data has been processed to remove the background trend variations in the geomagnetic components. At the Changchun station (Fig. 3a), the arrival time of the initial wave was approximately 60 - $62 \mathrm{~s}$ after the explosion and earlier in the Z component. Based on the distance between the observation station and the site of the explosion, the wave velocity was approximately $7.5-7.8 \mathrm{~km} \mathrm{~s}^{-1}$, close to the velocity of the Pn wave (head wave). The second wave arrived after $126 \mathrm{~s}$ with a longer period than the first one, and its velocity was approximately $3.7 \mathrm{~km} \mathrm{~s}^{-1}$, similar to the velocity of an S-wave or a Love wave. At the Dedu station (Fig. 3b), the Z component of the first wave arrived $103 \mathrm{~s}$ after the explosion, and the $\mathrm{H}$ component of this first wave arrived after $109 \mathrm{~s}$. Thus, its velocity was calculated as $7.6-8.0 \mathrm{~km} \mathrm{~s}^{-1}$, and it was identified as a Pn wave. The second long-period wave began $240 \mathrm{~s}$ after the explosion, with a velocity of $3.4 \mathrm{~km} \mathrm{~s}^{-1}$, resembling an S- or surface wave, or a superposition of both. Compared to the case described in section 3.1, the following are the prominent differences in this case: (i) Clear co-seismic signatures were detected at both stations with an obviously long time interval of $130 \mathrm{~s}$ between the two group signals at Dedu, corresponding to the arrival time of P- and $\mathrm{S}$-waves or surface waves. (ii) The variation in the amplitude of the signals, in this case, was quite large, especially in the $\mathrm{H}$ component, about $\pm 5 \mathrm{nT}$ at Changchun and $\pm 2 \mathrm{nT}$ at Dedu. (iii) Signals with a super-long period of $40 \mathrm{~s}$ that were detected approximately $300 \mathrm{~s}$ later in the above case were not recorded again at both stations in this case.

Due to the large magnitude of the event of 3 September 2017, another interesting co-seismic signature was detected at Dalian station in China (Fig. 1), at a distance of approximately $660 \mathrm{~km}$ from the explosion site, which is closer than Dedu. From the three components of the geomagnetic field measured at the Dalian station (Fig. 3c), no clear disturbances were observed in the $\mathrm{H}$ and $\mathrm{Z}$ components 10 min after the explosion. However, a few signals with a significant amplitude were detected in the declination (D) component $180 \mathrm{~s}$ onwards, with a maximum amplitude of about \pm 0.4 ar$\mathrm{cmin}$. The wave velocity was computed to be approximately $3.66 \mathrm{~km} \mathrm{~s}^{-1}$ with the period of $20 \mathrm{~s}$. Considering the time difference between the signals measured at Dalian station with the second group wave measured at Changchun and Dedu stations, the observations are consistent with the propagation law of surface wave to these three stations, which are located at different distances from the explosion source.

In order to verify the relationship between the geomagnetic field signals with the seismic waves, the seismic bulletin of the 3 September 2017 case was collected from the International Seismological Centre (ISC). Typical phases are plotted in Fig. 4 with their arrival times, including the Pn, P-, S-, and surface waves. The results show that between a distance of 3.3 to $16.9^{\circ}$, Pn can be clearly distinguished in the seismograms as the first arriving wave, and P- and $\mathrm{S}$-waves are subsequently detected. Further, the $\mathrm{S}$ - and $\mathrm{Lg}$ surface waves (crustal guided S-waves) and LR (Rayleigh waves) are observed to arrive at almost the same time for distances between 4 to $10^{\circ}$. These features are consistent with the observations of the geomagnetic field where the fastest signals at the beginning corresponds to a Pn wave, whereas the large-amplitude, long-period wave in the following time series is the surface wave or S-wave arriving within a very short arrival time. 

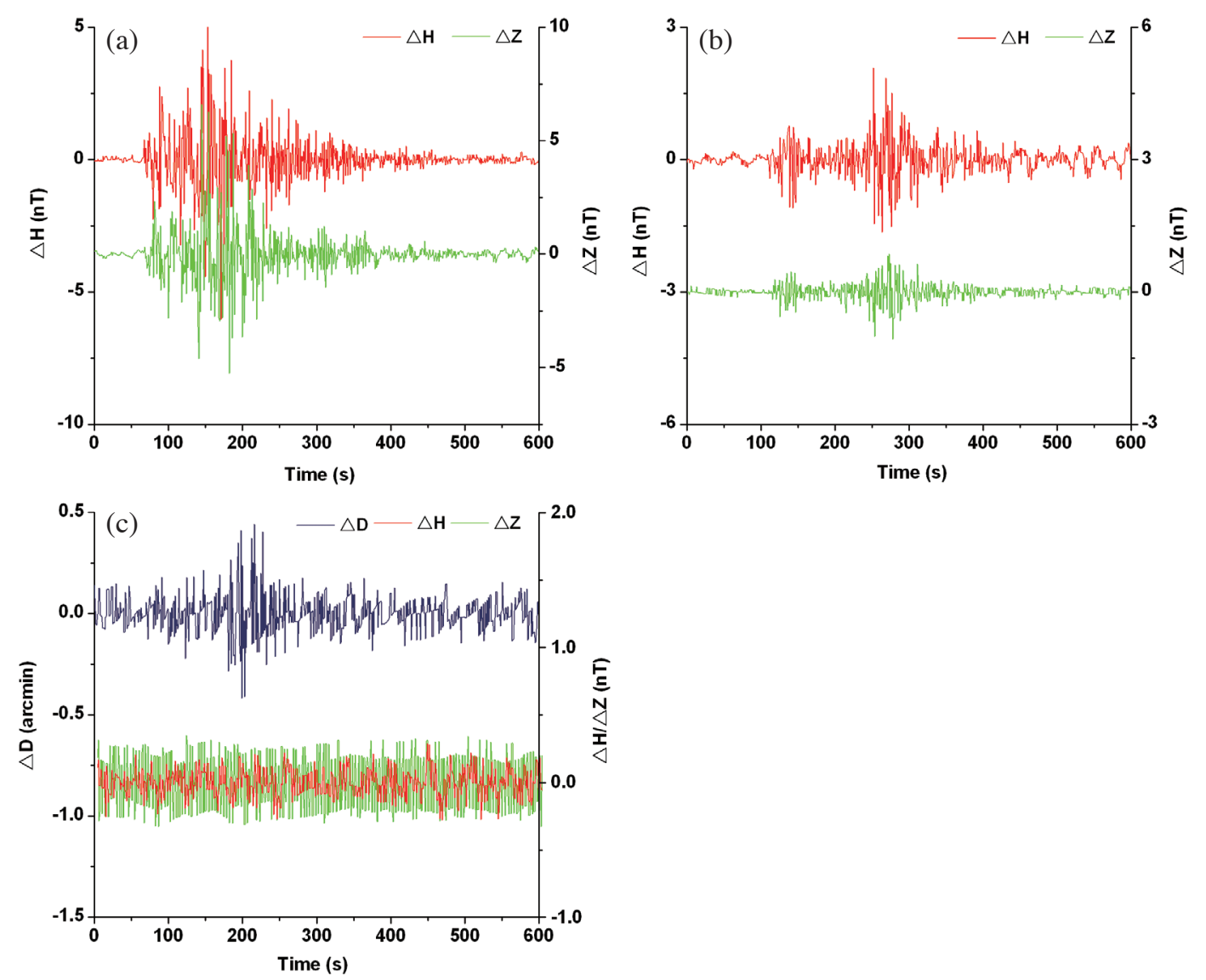

Fig. 3. Variation in the horizontal and vertical magnetic field signals measured in northeast China on 3 September 2017 at the (a) CNH, (b) DED, and (c) DLG stations.

(a)

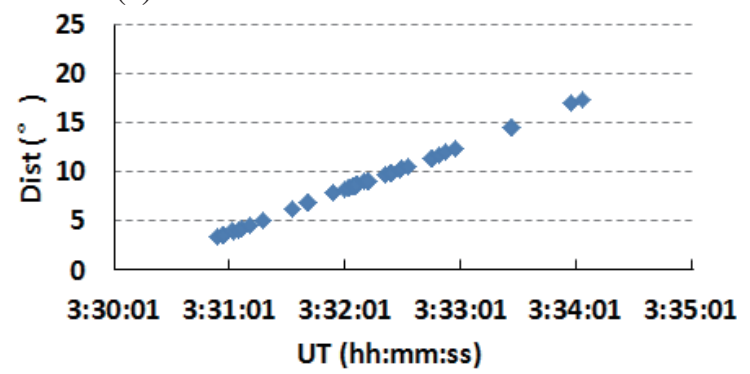

(b)

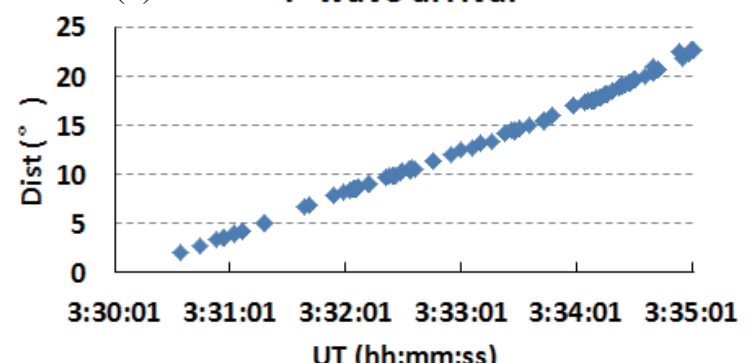

(c)

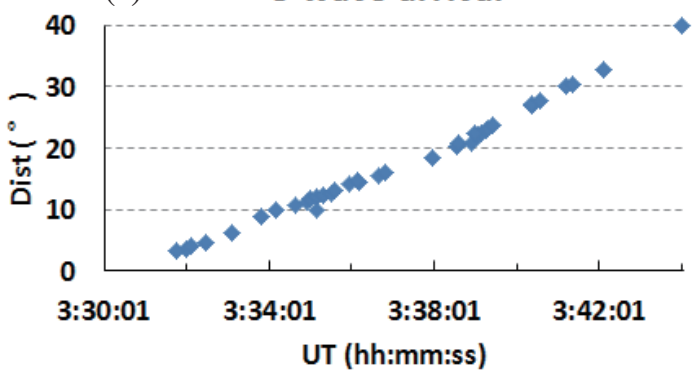

(d) Lg nad LR wave arrival

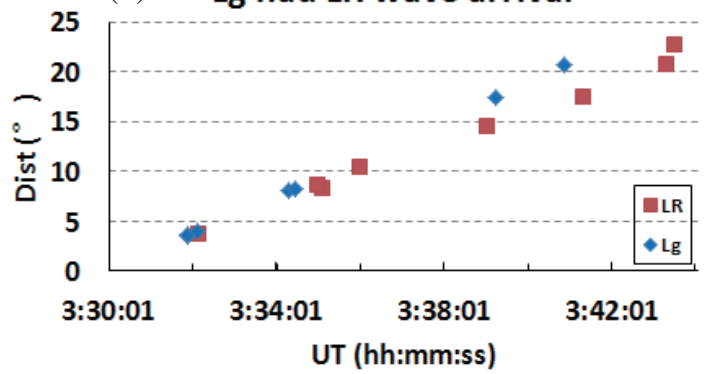

Fig. 4. Records of the seismic phases observed the case of 3 September 2017 (a) to (d) represent the Pn, P-, S-, and surface wave, respectively. 


\subsubsection{Electromagnetic Signals Measured in Japan}

As can be seen from Fig. 4, the arriving time of the surface waves is delayed compared to the S-wave beyond a distance of $10^{\circ}$. In order to study the characteristics of the geomagnetic field, which involves the measurement of surface waves far away from the explosion site of the event of 3 September 2017, co-located geomagnetic and geoelectric data were collected from four stations in Japan (indicated in Fig. 1). The distance from these stations to the source is approximately $10.1^{\circ}$ for $\mathrm{KNY}, 12.2^{\circ}$ for $\mathrm{KAK}, 15.3^{\circ}$ for $\mathrm{MMB}$, and $19.3^{\circ}$ for CBI. These distances have been obtained by simply computing the differences between the longitude and latitude to the source individually.

The $\mathrm{D}$ and $\mathrm{H}$ components of the original geomagnetic field observations done at the KAK, MMB, and KNY stations, and only the total magnetic field, F, measured at the CBI station (without the three-component observation at this station), between UT 03:30 - 04:00 on 3 September 2017 are shown in Fig. 5. The data sampling rate was $1 \mathrm{~Hz}$. Two groups of signals can be clearly seen from the figure. The first wave was detected only at the MMB station, with an arrival time of UT 03:35, which is more likely to be an $\mathrm{S}$-wave with a calculated velocity of about $4.2 \mathrm{~km} \mathrm{~s}^{-1}$. The second wave arrived at all four stations at almost the same time around UT 03:41, 10 min later than the first wave and about $637 \mathrm{~s}$ after the explosion. The interesting observation here was the simultaneous detection of the signal with a similar amplitude of $\pm 0.2 \mathrm{nT}$ at the four stations located at different distances from the source. The second feature was the regular sinusoidal waveforms in the following $15 \mathrm{~min}$, which resemble geomagnetic pulsations.

Three out of the four stations in Japan have geoelectric field detectors. Figure 6 presents the time series of the geoelectric field measured at KAK, MMB, and KNY stations, respectively. The regular sinusoidal waves were also detected and observed to persist in the two horizontal components between UT 03:40 - 04:00. At the MMB station, these sinusoidal waveforms were recorded much earlier than the other two stations, at UT 03:37 (Fig. 6b). Their velocity was about $3.5 \mathrm{~km} \mathrm{~s}^{-1}$, which is most likely to be a surface wave. It is difficult to define the start time of the signal waveforms detected in the other two stations due to a strong noise background in the geoelectric field observations. Although MMB is not the nearest station in Japan to the explosion source, co-seismic signatures were probably detected in the geomagnetic and geoelectric field. However, it was hard to confirm their detection since the same signals were detected at $\mathrm{CNH}$ and DED due to limited support from other stations in Japan. In order to verify whether the waves detected at UT 03:40 in the geomagnetic field, at the four stations shown in Figs. 5 and 6, are geomagnetic pulsations or not, the data from the CNH, DED, and DLG stations, and another remotely located station in Urumuqi (WMQ in
Fig. 1) in China were also checked for this time period after UT 03:40, and similar signals to those found in Japan were observed. Multiple observations illustrate that these sinusoidal signals were detected on a reasonably large spatial scale in the same time period, and they may not be induced by the explosions in North Korea but could be the geomagnetic pulsation signals from the lower ionosphere.

\subsection{Statistical Results from All Nuclear Tests}

The above-mentioned results highlight the sensitive feature of geomagnetic observations at the Chinese stations around the nuclear test site in North Korea. In order to compare the similarities and differences between the measured signals, information of the $\mathrm{CNH}$ station has been summarized in Table 2, in which the equivalent amount of explosive was calculated by the scientists at the University of Science and Technology of China. The results show that the $\mathrm{CNH}$ station is quite sensitive to the explosions from North Korea, and the co-seismic signatures were all clearly detected in five events, except for the first one, which does not have a geomagnetic data record from this station. In addition, three out of the five events showed the P-type wave, especially clearly on 12 February 2013 and 3 September 2017. The similarity between the detected signals is the approximate amplitude in the second to fifth events, which is within $0.3-0.4 \mathrm{nT}$ for the $\mathrm{H}$ component. The maximum amplitude of the $\mathrm{D}$ and $\mathrm{H}$ components, related to the $\mathrm{S}$ - or surface waves reached the first and the second highest velues, being \pm 5 and $\pm 0.4 \mathrm{nT}$ in the $\mathrm{H}$ component on 3 September 2017 and 12 February 2013, respectively. The seismic magnitude of the event that occurred on 12 February 2013 has been determined to be 4.9 (Table 2), which is equivalent to approximately $12.2 \mathrm{kt}$. Both the values are smaller than that corresponding to the event on 9 September 2016, which was of magnitude 5.0 and equivalent of $17.8 \mathrm{kt}$. This suggests that the magnitude of the 12 February 2013 event is probably underestimated, whereas that of 9 September 2016 might be overestimated due to its small amplitude in the geomagnetic field or the explosion mode being controlled and limited in this case. The equivalent and $\Delta \mathrm{H}$ amplitude in the five events shown in Table 2 exhibit a linear relationship with the correlation coefficient of 0.99 , which demonstrates that the co-seismic geomagnetic variation amplitude can quantitatively analyze the energy of explosions.

\section{DIGITAL SIMULATION OF CO-SEISMIC ELECTROMAGNETIC SIGNALS INDUCED BY EXPLOSION}

In the previous studies, the correlation between electromagnetic observations and seismic waves have been investigated widely (Hu and Gao 2011; Gao et al. 2014; Surkov et al. 2018). Taking the different fracture mechanisms of 

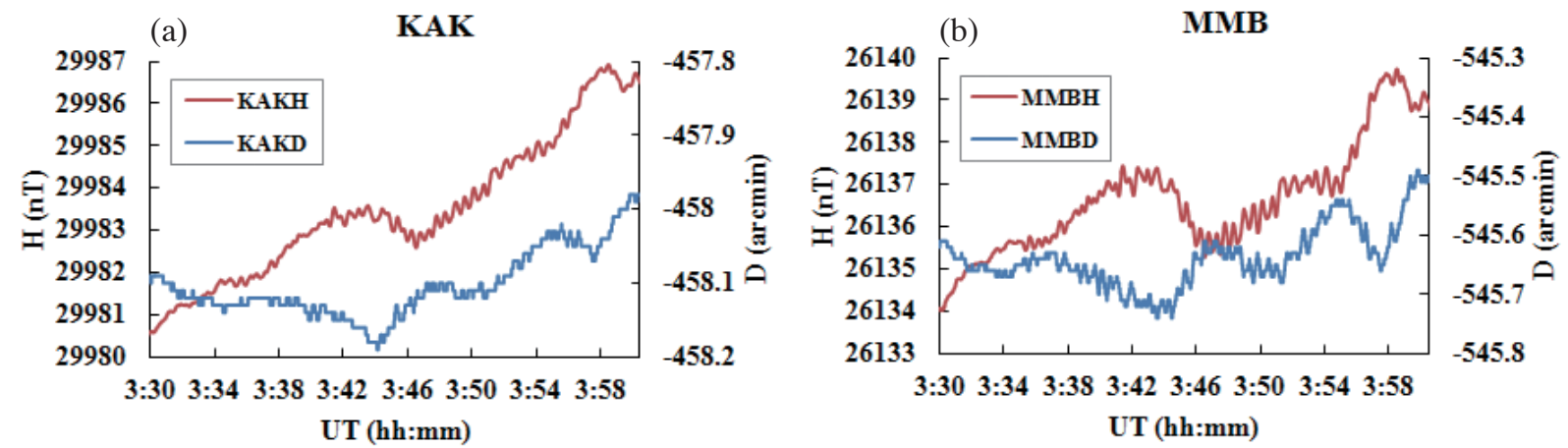

(c)

KNY

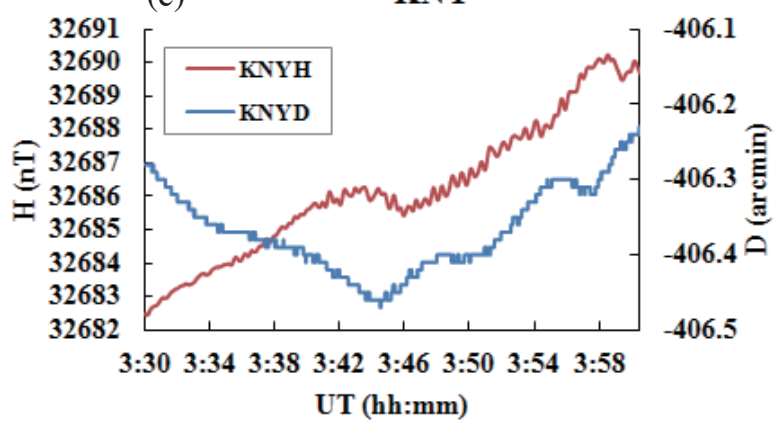

(d)

CBI

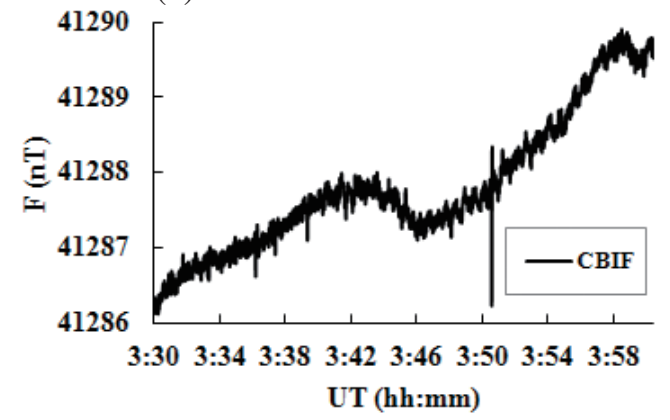

Fig. 5. Modulations in the geomagnetic components measured on 3 September 2017 at four stations. (a), (b), and (c) show the H component and D at the KAK, MMB, and KNY stations, respectively and (d) shows the total geomagnetic field, F, measured at the CBI station.
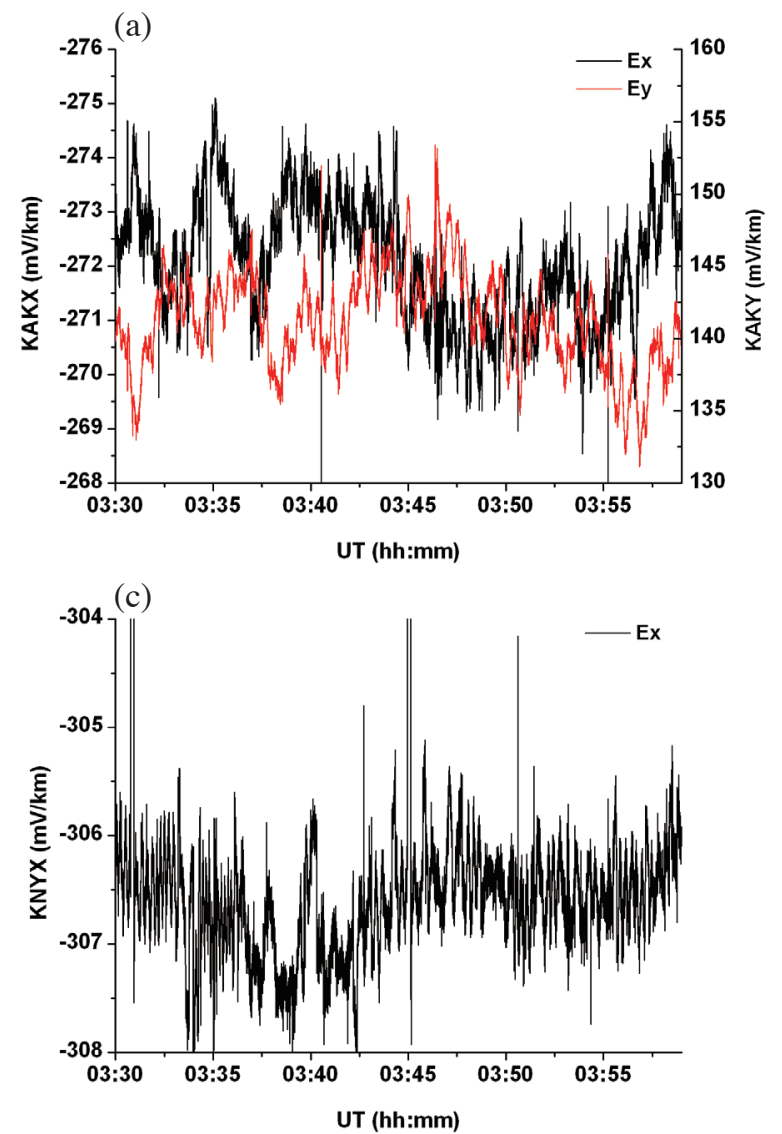

Fig. 6. Modulations of the Ex and Ey components of the geoelectric field measured at three stations on 3 September 2017. (a) and (b) show the Ex and Ey components measured at the KAK and MMB stations, respectively, whereas (c) shows the Ex component measured at the KNY station. 
Table 2. Statistical results of the EM signals related to the nuclear tests conducted in North Korea measured at the Changchun station.

\begin{tabular}{|c|c|c|c|c|c|}
\hline $\begin{array}{c}\text { Date } \\
\text { (yyyy-mm-dd) }\end{array}$ & Ms & $\begin{array}{l}\text { Equivalent } \\
(\mathbf{k t})\end{array}$ & $\begin{array}{c}\text { Arrival Time of P-type } \\
\text { wave (s) }\end{array}$ & $\begin{array}{c}\text { Maximal amplitude in D component } \\
\text { to surface wave (arcmin) }\end{array}$ & $\begin{array}{c}\text { Maximal amplitude in } \mathrm{H} \text { component } \\
\text { to surface wave (nT) }\end{array}$ \\
\hline 2006-10-9 & 4.0 & 0.48 & no data & no data & no data \\
\hline $2009-5-25$ & 4.3 & $7.0 \pm 1.9$ & not clear & \pm 0.32 & \pm 0.31 \\
\hline $2013-2-12$ & 4.9 & $12.2 \pm 3.8$ & 69 & \pm 0.88 & \pm 0.4 \\
\hline 2016-1-6 & 4.9 & $11.3 \pm 4.2$ & not clear & \pm 0.5 & \pm 0.37 \\
\hline 2016-9-9 & 5.0 & $17.8 \pm 5.9$ & 67 & \pm 0.25 & \pm 0.3 \\
\hline $2017-9-3$ & 6.3 & $108.3 \pm 48.1$ & 60 & \pm 5 & \pm 5 \\
\hline
\end{tabular}

explosions with the natural earthquakes into account, a digital simulation has been performed for understanding the strong response observed in the geomagnetic field measured in northeast China. A seismic station named SGT $\left(44.1^{\circ} \mathrm{N}\right.$, $\left.124.9^{\circ} \mathrm{E}\right)$ was selected due to its close proximity of approximately $56 \mathrm{~km}$ to the $\mathrm{CNH}$ geomagnetic station. Figure 7 shows the three components of the seismic wave signals at the SGT station and Bz (the vertical component of geomagnetic field) at the $\mathrm{CNH}$ station from top to bottom. From left to right is shown the raw data and the signals in the two different frequency bands in the range of $0.05-0.1$ and 0.1 $-0.15 \mathrm{~Hz}$ after filtering are shown for all four components measured $250 \mathrm{~s}$ after the explosion event of 3 September 2017. From the figure, it can be seen that the Bz signal from the $\mathrm{CNH}$ station shows a good correlation with the seismic records from the SGT station in the raw data. However, the arrival time of the Pn waves in the seismograms is a little earlier than that of the Bz signal. It should be noted that the seismic waveforms have a high sampling rate of $100 \mathrm{~Hz}$, whereas the geomagnetic data has a sampling rate of only $1 \mathrm{~Hz}$. In the seismogram from the SGT station, a Pg wave was clearly observed in $\mathrm{Vz}$ component, and a Love wave arrived $140 \mathrm{~s}$ after the explosion, which also can be found in the Bz signal from the CNH station between $140-190 \mathrm{~s}$. In order to plot them in the same frequency band, low-pass filtering was applied to all four signal components. After filtering, most seismic phases almost disappeared in the 0.05 $0.1 \mathrm{~Hz}$ frequency band, except for the surface waves around $150 \mathrm{~s}$ in the three signal components. In the $0.1-0.15 \mathrm{~Hz}$ band, significant amplitude signals were observed, and the surface waves in the $\mathrm{Y}$ component of seismic waves were observed $150 \mathrm{~s}$ earlier than those in the $\mathrm{X}$ and $\mathrm{Z}$ components. The Bz signals obtained from the $\mathrm{CNH}$ station after filtering were observed to be quite different compared to the seismic waves, with the strong signals starting at $60-70 \mathrm{~s}$ with an almost equally large-amplitude lasting till $240 \mathrm{~s}$. This indicates that other than the surface waves, in contrast to expectation, the geomagnetic field also has a strong response to the body waves. With an increase in the range of the frequency band, the similarity between $\mathrm{Vy}$ and $\mathrm{Bz}$ is observed to be enhanced, especially after $130 \mathrm{~s}$ (Fig. 7).
There are several possible candidate mechanisms that can explain the response of the geomagnetic field to the seismic waves, including electrokinetic effects $(\mathrm{Hu}$ and Gao 2011), dynamo effects (Gao et al. 2019), and shaking of a magnetic rod (Jiang et al. 2018). In this work, we have simulated the co-seismic magnetic signals generated by the nuclear explosion by incorporating these three mechanisms and have investigated which of them contributes predominantly to the observed signals. When modeling the magnetic signals caused by magnetic rod shaking, we have used the algorithm given by Jiang et al. (2018), in which the seismic records observed near the magnetic sensor are required as input. Because there is no co-located seismometer installed at $\mathrm{CNH}$, we have used the records from the SGT station (Fig. 7) as an alternative.

While modeling the electrokinetic effect and the dynamo effect, two kinds of parameters, namely the source parameters and the underground velocity model, are required. The source parameters were chosen from the work of Liu et al. (2018). Crust2.0 (Bassin et al. 2000), which is a fourlayer model (see Table 3 ), was chosen as the velocity model. Before simulating the magnetic data, the seismic signals from the SGT station were calculated first. The simulated seismic signals agree well with the observed seismic data, proving that the source and velocity models are suitable. The magnetic response arising from the electrokinetic effect was calculated by using the method and code developed by Hu and Gao (2011). The magnetic signals from the dynamo effect (or motional induction effect) were simulated by the method developed by Gao et al. (2018). In the modeling processes, parameters that control the seismicto-EM conversion are also required. For example, in the electrokinetic modeling, the values of the porosity of the underground rock, pore fluid salinity, etc., are required to be specified. However, these parameters are unfortunately not well known. As a consequence, these parameters were taken as variables in order to fit the observed data. However, the specifications of these parameters were not arbitrary. They were chosen to have typical values or values within a reasonable range. In addition, because of the limitations of the velocity model and the low sampling rate of $1 \mathrm{~Hz}$ in 
2017-09-03 03:30:01 M6.3 North Korea
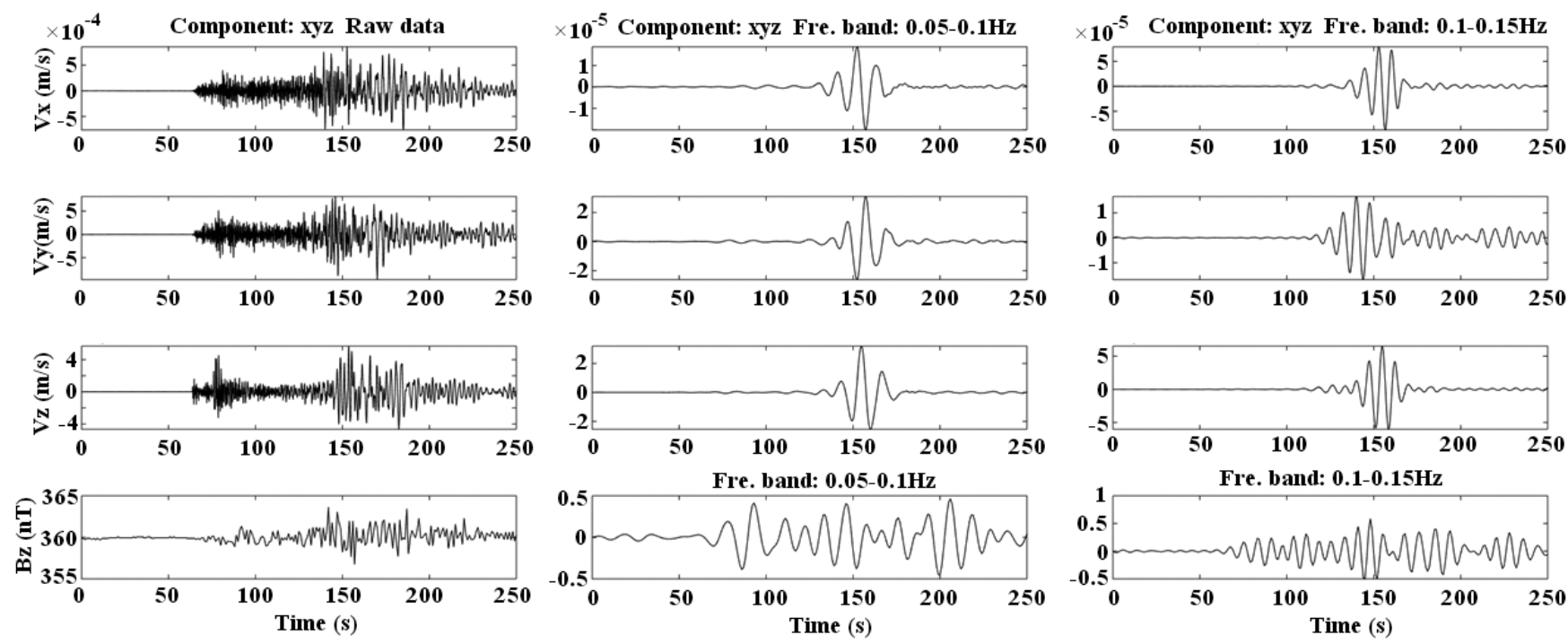

Fig. 7. Seismic waveforms (velocity components Vx, Vy, and Vz in the three directions) measured by the SGT station and Bz measured at the Changchun station after the event on 3 September 2017 (left: raw data, middle: $0.05-0.1 \mathrm{~Hz}$ frequency band, right: $0.1-0.15 \mathrm{~Hz}$ frequency band).

Table 3. Parameters of the crustal model used in the simulation.

\begin{tabular}{ccccc}
\hline Parameter & $\mathbf{1}^{\text {st }}$ layer & $\mathbf{2}^{\text {nd }}$ layer & $\mathbf{3}^{\text {rd }}$ layer & $\mathbf{4}^{\text {th }}$ layer \\
\hline $\mathrm{Vp}\left(\mathrm{km} \mathrm{s}^{-1}\right)$ & 6.2 & 6.4 & 6.8 & 8.2 \\
$\mathrm{Vs}\left(\mathrm{km} \mathrm{s}^{-1}\right)$ & 3.6 & 3.6 & 3.8 & 4.7 \\
$\mathrm{Qp}$ & 2000 & 2000 & 2000 & 2000 \\
$\mathrm{Qs}$ & 2000 & 2000 & 2000 & 2000 \\
$\sigma\left(\mathrm{S} \mathrm{m}^{-1}\right)$ & 1 & 0.1 & 0.1 & 0.1 \\
$\mathrm{H}(\mathrm{km})$ & 13 & 12 & 12 & \\
\hline
\end{tabular}

the observed geomagnetic data, the frequency range in the modeling processes was below $0.5 \mathrm{~Hz}$. The source used in this study was a pulse source with a finite frequency band. The time function was expressed by

$$
\begin{aligned}
& s_{0}(t)= \\
& \left\{\begin{array}{c}
\frac{1}{2}\left[1+\cos \frac{2 \pi}{T_{c}}\left(t-\frac{T_{c}}{2}\right)\right] \cos 2 \pi f_{0}\left(t-\frac{T_{c}}{2}\right), 0 \leq t \leq T \\
0, t<0 \text { or } t>T_{c}
\end{array}\right.
\end{aligned}
$$

where $f_{0}$ and $T_{c}$ denote the center frequency and the width of the pulse, respectively. In the following simulations, they were chosen to be $0.2 \mathrm{~Hz}$ and $10 \mathrm{~s}$, respectively.

The simulation results corresponding to all three mechanisms are shown in Fig. 8. A comparison of the simulated magnetic signals resulting from the electrokinetic effects, within a frequency range of $0.1-0.2 \mathrm{~Hz}$, with those obtained from the $\mathrm{CNH}$ station, is shown in Fig. 8a from which only the signals corresponding to the surface waves can be identified. The amplitude of the simulated signals (red line) is three orders of magnitude smaller than the observed data (black line). The simulated magnetic signal was obtained by setting the fluid salinity of the first layer to be $1 \times 10^{-5} \mathrm{~mol} \mathrm{~L}^{-1}$ and the corresponding conductivity of 1.1 $\times 10^{-4} \mathrm{~S} \mathrm{~m}^{-1}$. A previous study by Gao (2010) demonstrates that the amplitude of the magnetic signal increases with a decrease in the pore fluid salinity, however decreasing the salinity results in a decrease in the conductivity of the medium. Our simulations show that when the salinity reduces to $1 \times 10^{-8} \mathrm{~mol} \mathrm{~L}^{-1}$ (the corresponding rock conductivity is as low as $1 \times 10^{-6} \mathrm{~S} \mathrm{~m}^{-1}$, which is uncommon for real Earth medium), the amplitude of the magnetic field is still weaker than $0.1 \mathrm{nT}$. This suggests that the observed large magnetic signals are unlikely to be caused by the electrokinetic effect.

Figure $8 \mathrm{~b}$ shows the simulated magnetic signals arising from the dynamo effects within a frequency band of 0.1 $0.2 \mathrm{~Hz}$. The value of the conductivity in each layer is listed in Table 3. Similar to the results in Fig. 8a, only the signals accompanying the surface wave are apparent in this model. 

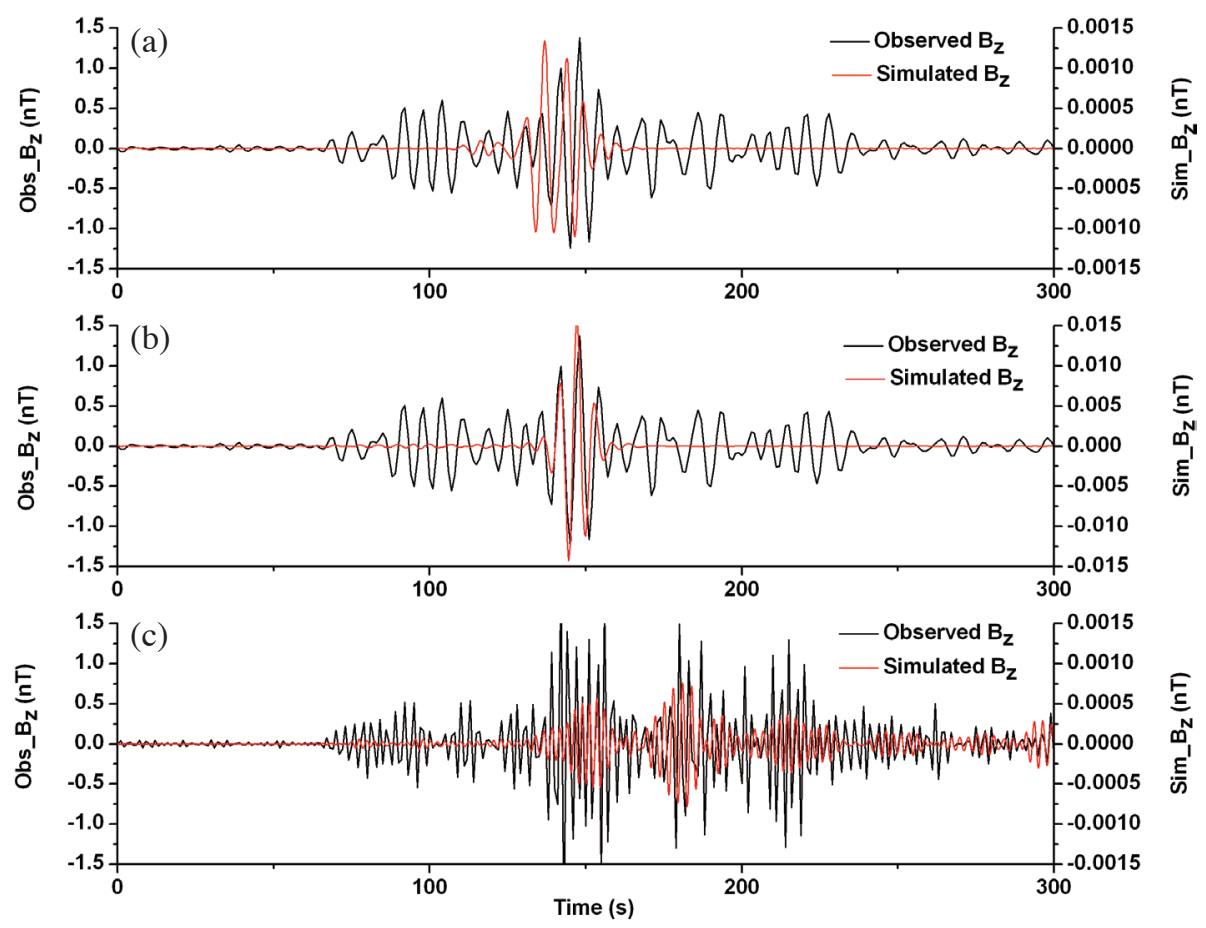

Fig. 8. Comparison between the observed and simulated Bz signal arising due to the three effects (a) $0.1-0.2 \mathrm{~Hz}$ filtered data resulting from the electrokinetic effect, (b) $0.1-0.2 \mathrm{~Hz}$ filtered data resulting from the dynamo effect, and (c) $0.3-0.45 \mathrm{~Hz}$ filtered data resulting from the shaking of a magnetic rod.

According to the work of Gao et al. (2018), the magnetic field mainly depends on the conductivity of the first layer, where the receiver is located, and its magnitude increases with the augmentation of conductivity. It should be noted that the conductivity of the first layer is set to $1 \mathrm{~S} \mathrm{~m}^{-1}$, which is a high value for the underground medium. However, the amplitude of the simulated magnetic field (red line) is two orders of magnitude smaller than the observed data (black line in Fig. 8b). Even on increasing the conductivity to a value as high as $10^{7} \mathrm{~S} \mathrm{~m}^{-1}$, which is an impossible value for the real Earth medium, the simulated magnetic field is still two orders of magnitude smaller than the observed signals.

Figure $8 \mathrm{c}$ illustrates the magnetic signals in the frequency band of $0.3-0.45 \mathrm{~Hz}$ obtained by shaking a magnetic rod. Most groups of waveforms can be captured under this effect, including the effects of body waves, and thus the clear seismic phases in the data of the $\mathrm{CNH}$ geomagnetic measurement could be induced to a large extent by this effect. However, the amplitude of the simulated waveforms (red line in Fig. 8c) is unfortunately still quite small, approximately three orders of magnitude lower than the actual observations (black line in Fig. 8c) corresponding to signals due to the electrokinetic effect. The disagreement between the simulated and observed magnetic signals could be due to the fact that the method given by Jiang et al. (2018) is for estimating the magnetic signal caused by the rotation of the coil magnetometer, whereas the magnetic signal at the $\mathrm{CNH}$ station was measured by a fluxgate-type magnetometer.

\section{DISCUSSION AND CONCLUSIONS}

Eleman (1966) discussed the response of magnetic instruments to seismic waves and suggested that ULF magnetographs could be used as supplementary seismic recorders due to the direct seismograph effect. However, he also found that the seismic waves do generate real magnetic waves induced by piezomagnetic oscillations with enhanced crustal conductivity. In this work, we have simulated the magnetic waves resulting due to the electrokinetic effect, dynamo effect, and shaking effect of a magnetic rod. However, the amplitude of the simulated magnetic signals is too small compared to the observed data, even with the three effects acting together. This indicates that there could be other factors affecting the geomagnetic observations that have not been accounted for in the simulations. From the previous observations related to earthquakes and explosions introduced in the introduction part of this paper, most of the co-seismic wave magnetic disturbances detected in close proximity to these events had amplitudes in the range of pT to nT. Thus, amplitude variations in the range of $2-5 \mathrm{nT}$ detected at the Dedu and Changchun stations were considerably large even though they were measured at such far distances of a few hundred kilometers away with the source. Other than the three effects incorporated in this work, the measured signals might include an effect from the observation system itself. To verify this aspect, we collected the co-seismic EM data corresponding to the Japan Mw 9.0 earthquake of 11 March 
2011, in which the $\mathrm{H}$ component measured at the MMB station detected a maximum variation of approximately $\pm 0.4 \mathrm{nT}$. On the other hand, the same signal component measured at the CNH station, which is located at a similar latitude to the MMB station, had an amplitude of about $\pm 10 \mathrm{nT}$. Even if the difference in the distances between both stations from the epicenter is not considered, the perturbations measured at the $\mathrm{CNH}$ station were approximately 25 times larger than those measured at the MMB station. Using the Chinese geomagnetic network data, Wang et al. (2019) studied the co-seismic geomagnetic disturbances detected from the Wenchuan Mw 7.9 earthquake that occurred on 12 May 2008. They found significantly large amplitude variations of approximately $1000 \mathrm{nT}$ at the station closest to the epicenter. Further, large differences in amplitude were observed at different stations, which demonstrate a certain correlation between direct selection and site selection. It should be noted that the geomagnetic observations in China all detected abnormally large amplitude co-seismic signatures. This systematic error in the instrument in China may lead to significant amplification of the signal amplitude to tens or even hundreds of times. Thus, the analysis of the variations in the magnetic field observations should be paid more attention to when using them for other research applications in order to avoid an erroneous estimation of the signal amplitude. Observations and simulation results indicate that co-seismic geomagnetic disturbances include not only the vibration of the magnetometer but also the excitation of electromagnetic waves induced from the seismic waves. The latter indeed depend on the site selection effect, where certain special underground structures or high conductivity media help in enhancing the electromagnetic signals at these points. This site selection effect can explain the large differences in the observed signals originating from the same source at DLG with those at CNH or DED stations.

Zhao et al. (2014) studied the seismograms recorded during the nuclear tests and found that the seismograph recorded abrupt P-wave arrivals, well-developed short-period Rayleigh waves, and weak $\mathrm{Lg}$ waves at the MDJ station in northeast China located at a distance of $372 \mathrm{~km}$ from the explosion source of three tests conducted in 2006, 2009, and 2013 in North Korea (Table 1). In addition, the P/S spectral ratios proved to be powerful in discriminating the explosions from the natural earthquakes above $2 \mathrm{~Hz}$ on the basis of the data from a local seismic network. In the case of the nuclear test that was conducted on 3 September 2017, the seismograms measured by Liu et al. (2018) also showed similar amplitude Pg and Lg signals in the local area of hundreds of kilometers, which was also shown in the seismogram measured at the SGT station in Fig. 7. As compared to the results reported by Zhao et al. (2014), the Love wave observed in this work for the event of 3 September 2017, was well developed and was not as weak as those in the previous nuclear tests. Due to the low sampling rate of the geomagnetic data, it is difficult to recognize the features in the high-frequency band. However, from the filtering results, the ratio of the P-wave-related to the Lg-wave-related EM signal amplitude was observed to be higher in the low-frequency band, such as the $0.05-0.1 \mathrm{~Hz}$ band, and the ratio decreased with increasing magnitude of the frequency band at $0.3-0.45 \mathrm{~Hz}$.

From a comparison of the two events on 3 September 2017 and 9 September 2016, it is observed that due to the increase in the explosion power of the 2017 event, body and surface waves were clearly recorded at the CNH and DED stations in China, however, for the event of 2016, only weak waves were detected at the $\mathrm{CNH}$ station. On 9 September 2016, an unusual 40 s periodical wave occurred between 280 and $360 \mathrm{~s}$ after the explosion at both stations, as shown in Fig. 2. In order to verify whether this was a surface-waverelated EM signal or not, geomagnetic data from Manzhouli and Urumuqi in China were collected, and the same wave was revealed to be recorded at the same time period, having a similar amplitude to that recorded at Changchun and Dedu stations. Thus, it could be concluded that the detected signal was not the surface-wave EM response during the event of 2016. Taking account of its period reveals that it belonged to Pc3. On combining the observation of pulsation occurring on 3 September 2017, at the Japanese and Chinese stations, it was interestingly found that both the events were followed by geomagnetic pulsations, but were not a local phenomenon. The difference in their arrival times and amplitude attenuation in both data did not have any relationship to the distance from the epicenter. They were different from the pulsation observed only at one station after the Sumatra earthquake in 2004 (Iyemori et al. 2005), and thus these signals could be excluded from being related to the nuclear tests. According to the statistical results on Pc3 signals recorded in the Beijing region of China (Yang and Feng 1985), Pc3 signals have seasonal variations with frequent high occurrences in spring and autumn and reach maximum intensities in autumn for measurements at $10-20 \mathrm{~s}$ and 30 - 40 s periods. The pulsations observed after both nuclear tests are consistent with this.

From the EM observations done in China and Japan, related to the nuclear tests conducted in North Korea, clear co-seismic EM signals were observed at the geomagnetic stations in northeast China. Although the instrument could be magnifying these signals by tens of times, it also exhibits a high sensitive feature of the $\mathrm{CNH}$ and DED stations in China, even to P-waves. In the geomagnetic observations analyzed in this work, detailed information was revealed about the explosion events in North Korea. The following conclusions can be drawn from our study:

(1) After the most powerful nuclear test on 3 September 2017, strong co-seismic EM signals were detected at three geomagnetic stations in northeast China, located between 400 and $850 \mathrm{~km}$ from the explosion site. The signals exhibited amplitudes of $\pm 5 \mathrm{nT}$ for the $\mathrm{H}$ 
component of the geomagnetic field at the $\mathrm{CNH}$ station. Among other events between 2009 and 2016, the maximum amplitude of the $\mathrm{H}$ component corresponding to the surface wave was observed to be similar for all signals, within $0.3-0.4 \mathrm{nT}$ measured at the $\mathrm{CNH}$ station.

(2) Within a distance of 1000 - $2000 \mathrm{~km}$, no stations in China and Japan recorded definite co-seismic wave EM disturbances. This could be related to the small amplitude of the S-wave and surface waves excited by the explosions in North Korea.

(3) The obvious difference between the geomagnetic observations from the $\mathrm{CNH}$ station and the seismograms obtained from the SGT station is that the co-seismic EM disturbances persisted for a longer duration with large amplitudes, especially accompanying the body waves after the explosion, even with an identical strength to the amplitude induced by the surface wave.

(4) A comparison of the simulation results obtained by employing the three models indicates that the electrokinetic and dynamo effects mainly contribute to the EM responses to the surface waves, and the vibration of the magnetic rod may explain the large signals observed after the S- and surface waves. However, the amplitudes of the simulated signals are very small, indicating that the three models incorporated in this work are unable to explain the data of actual observations from the geomagnetic stations in China located at a large distance from the explosion source. In addition, no suitable effect is able to explain the large disturbances after the P-wave observed in the low-frequency band.

(5) A comparison of the geomagnetic field data from the Chinese stations with those obtained from the Japanese stations showed that the fluxgate magnetometer widely used in China might have a considerable systematic amplification. However, the CNH and DED stations showed a highly sensitive site selection effect. Thus, a combination of these observations with the simulation results helps in understanding the mechanism of the seismic waves that induce electromagnetic disturbances.

Acknowledgements This paper is supported by National Key R\&D Program of China (Grant no. 2018YFC1503506), NSFC project (41674156), and China Seismic Experimental Site (2018CSES0203). The authors thank the National Geomagnetic Network Center in China (http://www.geomag. org.cn/default.aspx), and Kakioka Magnetic Observatory in Japan to share the geomagnetic and electric data (http:// www.kakioka-jma.go.jp/en/index.html), and appreciate CENC for the catalog of blasts at http://news.ceic.ac.cn/index.html?time $=1557908573$ and ISC for the seismic phase information on the website of http://www.isc.ac.uk/iscbulletin/search/bulletin/. The authors appreciate the comments and good suggestions from anonymous reviewers to improve this paper.

\section{REFERENCES}

Abdul Azeez, K. K., C. Manoj, K. Veeraswamy, and T. Harinarayana, 2009: Co-seismic EM signals in magnetotelluric measurement - A case study during Bhuj earthquake $\left(26^{\text {th }}\right.$ January 2001), India. Earth Planets Space, 61, 973-981, doi: 10.1186/bf03352947. [Link]

Anisimov, S. V., M. B. Gokhberg, E. A. Ivanov, M. V. Pedanov, N. N. Rusakov, V. A. Troitskaya, and V. I. Goncharov, 1985: Short period vibrations of the Earth's electromagnetic field due to industrial explosion. Rep. USSR Acad. Sci. (Dokl. Akad. Nauk. SSSR) Engl. Transl., 281, 556-559.

Bassin, C. G. L., G. Laske, and G. Masters, 2000: The current limits of resolution for surface wave tomography in North America. Eos, Trans. AGU, 81, F897.

Chen, C.-R., J.-Y. Liu, C.-H. Chen, T.-Y. Wu, H.-Y. Yen, S. Wen, B.-S. Huang, C.-H. Lin, C.-M. Lin, and H.-H. Hsieh, 2019: Co-seismic geomagnetic fluctuations and atmospheric disturbances during the 2018 M 6.2 Hualien Earthquake. Terr. Atmos. Ocean. Sci., 30, 449-465, doi: 10.3319/TAO.2019.03.11.01. [Link]

Eleman, F., 1966: The response of magnetic instruments to earthquake waves. J. Geomagn. Geoelectr., 18, 43-72, doi: 10.5636/jgg.18.43. [Link]

Gao, Y., 2010: Simulation of earthquake-induced electromagnetic wave field due to the electrokinetic effect. Ph.D. Thesis, Harbin Institute of Technology, Harbin, China, 167 pp. Available at https://www.docin. com/p-808719585.html.

Gao, Y., X. Chen, H. Hu, J. Wen, J. Tang, and G. Fang, 2014: Induced electromagnetic field by seismic waves in Earth's magnetic field. J. Geophys. Res., 119, 56515685, doi: 10.1002/2014JB010962. [Link]

Gao, Y., J. Wen, X. Chen, and H. Hu, 2018: Electromagnetic responses to an earthquake source due to the motional induction effect in a 2D layered structure. Japan Geoscience Union meeting 2018, MIS03-02. Available at https://confit.atlas.jp/guide/event-img/jpgu2018/ MIS03-02/public/pdf?lang=ja.

Gao, Y., D. Wang, C. Yao, W. Guan, H. Hu, J. Wen, W. Zhang, P. Tong, and Q. Yang, 2019: Simulation of seismoelectric waves using finite-difference frequency-domain method: 2-D SHTE mode. Geophys. J. Int., 216, 414-438, doi: 10.1093/gji/ggy433. [Link]

Garambois, S. and M. Dietrich, 2001: Seismoelectric wave conversions in porous media: Field measurements and transfer function analysis. Geophysics, 66, 1417-1430, doi: 10.1190/1.1487087. [Link]

Gershenzon, N. I., M. B. Gokhberg, and S. L. Yunga, 1993: On the electromagnetic field of an earthquake focus. Phys. Earth Planet. Inter., 77, 13-19, doi: 10.1016/0031-9201(93)90030-d. [Link]

Honkura, Y., A. M. Işikara, N. Oshiman, A. Ito, B. Üçer, 
Ş. Bariş, M. K. Tunçer, M. Matsushima, R. Pektaş, C. Çelik, S. B. Tank, F. Takahashi, M. Nakanishi, R. Yoshimura, Y. Ikeda, and T. Komut, 2000: Preliminary results of multidisciplinary observations before, during and after the Kocaeli (Izmit) earthquake in the western part of the North Anatolian Fault Zone. Earth Planets Space, 52, 293-298, doi: 10.1186/BF03351638. [Link]

Hu, H. and Y. Gao, 2011: Electromagnetic Field Generated by a Finite Fault Due to Electrokinetic Effect. J. Geophys. Res., 116, B08302, doi: 10.1029/2010JB007958. [Link]

Iyemori, T., M. Nose, D. Han, Y. Gao, M. Hashizume, N. Choosakul, H. Shinagawa, Y. Tanaka, M. Utsugi, A. Saito, H. McCreadie, Y. Odagi, and F. Yang, 2005: Geomagnetic pulsations caused by the Sumatra earthquake on December 26, 2004. Geophys. Res. Lett., 32, L20807, doi: 10.1029/2005GL024083. [Link]

Jiang, L., Y. Xu, L. Zhu, Y. Liu, D. Li, and R. Huang, 2018: Rotation-induced magnetic field in a coil magnetometer generated by seismic waves. Geophys. J. Int., 212, 743-759, doi: 10.1093/gji/ggx423. [Link]

Liu, J., L. Li, J. Zahradník, E. Sokos, C. Liu, and X. Tian, 2018: North Korea's 2017 test and its nontectonic aftershock. Geophys. Res. Lett., 45, 3017-3025, doi: 10.1002/2018GL077095. [Link]

Liu, J.-Y., C.-H. Chen, T.-Y. Wu, H.-C. Chen, K. Hattori, I.-C. Yang, T. Bleier, K. Kappler, Y. Xia, W. Chen, and Z. Liu, 2017: Co-seismic signatures in magnetometer, geophone, and infrasound data during the Meinong Earthquake. Terr. Atmos. Ocean. Sci., 28, 683692, doi: 10.3319/TAO.2017.03.05.01. [Link]

Nagao, T., Y. Orihara, T. Yamaguchi, I. Takahashi, K. Hattori, Y. Noda, K. Sayanagi, and S. Uyeda, 2000: Co-seismic geoelectric potential changes observed in Japan. Geophys. Res. Lett., 27, 1535-1538, doi: 10.1029/1999gl005440. [Link]

Surkov, V. V., V. A. Pilipenko, and A. K. Sinha, 2018: Possible mechanisms of co-seismic electromagnetic effect. Acta Geod. Geophys., 53, 157-170, doi: 10.1007/ s40328-018-0211-6. [Link]

Sweeney, J. J., 1989: An investigation of the usefulness of extremely low-frequency electromagnetic measurements for treaty verification. Technical Report UCRL53899, Lawrence Livermore National Laboratory, CA, United States, 59 pp, doi: 10.2172/6294530. [Link]

Tang, J., Y. Zhan, L.-F. Wang, Z.-Y. Dong, G.-Z. Zhao, and J.-L. Xu, 2010: Electromagnetic coseismic effect associated with aftershock of Wenchuan $M_{\mathrm{s}} 8.0$ earthquake. Chin. J. Geophys., 53, 526-531, doi: 10.3969/j. issn.0001-5733.2010.03.006. (in Chinese with English abstract) [Link]

Wang, Y., T. Xie, Y. An, C. Yue, J. Wang, C. Yu, L. Yao, and J. Lu, 2019: Characteristics of the coseismic geomagnetic disturbances recorded during the $2008 M_{\mathrm{w}}$ 7.9 Wenchuan Earthquake and two unexplained problems. Earth Planet. Phys., 3, 435-443, doi: 10.26464/ epp2019043. [Link]

Widarto, D. S., T. Mogi, Y. Tanaka, T. Nagao, K. Hattori, and S. Uyeda, 2009: Co-seismic geoelectrical potential changes associated with the June 4, 2000's earthquake (Mw7.9) in Bengkulu, Indonesia. Phys. Chem. Earth, 34, 373-379, doi: 10.1016/j.pce.2008.09.009. [Link]

Yamazaki, K., 2011: Enhancement of co-seismic piezomagnetic signals near the edges of magnetization anomalies in the Earth's crust. Earth Planets Space, 63, 111118, doi: 10.5047/eps.2010.12.001. [Link]

Yang, S. and Q. Feng, 1985: The statistical analysis of Pc3 geomagnetic micropulsation in Beijing. Chinese Journal of Space Science, 5, 279-285. (in Chinese with English abstract)

Yen, H.-Y., C.-R. Chen, Y.-T. Lo, T.-C. Shin, and Q. Li, 2015: Seismo-geomagnetic pulsations triggered by Rayleigh waves of the 11 March 2011 M 9.0 Tohokuoki earthquake. Terr. Atmos. Ocean. Sci., 26, 95-101, doi: 10.3319/TAO.2014.10.09.01(T). [Link]

Zhao, L.-F., X.-B. Xie, W.-M. Wang, and Z.-X. Yao, 2014: The 12 February 2013 North Korean underground nuclear Test. Seismol. Res. Lett., 85, 130-134, doi: 10.1785/0220130103. [Link] 